\title{
Rapid cardiac T1 mapping within two heartbeats
}

\author{
Elodie Breton*, Daniel Kim, Sohae Chung, Leon Axel \\ From 2011 SCMR/Euro CMR Joint Scientific Sessions \\ Nice, France. 3-6 February 2011
}

\section{Introduction}

Late gadolinium enhancement (LGE) imaging is an important CMR method than can detect salvageable myocardium after myocardial infarction [1-2]. Recently, $\mathrm{T}_{2}$-weighted-imaging has gained a significant interest to assess myocardial edema [3]. However, clinical interpretation of $\mathrm{T}_{2}$-weighted-imaging could be hindered by surface coil effects which yield non-uniform signals. Multi-point $\mathrm{T}_{1}$ mapping approaches, such as Modified Look-Locker inversion recovery (MOLLI) [4], have been proposed to measure myocardial $\mathrm{T}_{1}$, but, as a multiple heartbeat acquisition, it may be sensitive to cardiac motion and arrhythmia. We propose to develop a 2second cardiac $\mathrm{T}_{1}$ mapping pulse sequence for assessment of myocardial edema (pre-contrast) and infarction (post contrast) in patients with acute myocardial infarction.

\section{Purpose}

To develop and validate a cardiac $\mathrm{T}_{1}$-mapping technique.

\section{Methods}

The proposed $\mathrm{T}_{1}$-mapping acquisition consists of 2 TurboFLASH images with centric k-space ordering: proton density-weighted (PDw) image in the first heartbeat and saturation recovery (SR) $T_{1} w$ acquisition in the second heartbeat. A robust non-selective saturation pulse [5] was used to achieve uniform saturation of magnetization. A long delay time $=500 \mathrm{~ms}$ was used to achieve adequate signal-to-noise ratio. The $\mathrm{T}_{1} \mathrm{w}$-image was normalized by the PDw image to correct for unknown equilibrium magnetization and receiver coil sensitivity. $\mathrm{T}_{1}$ was calculated algebraically assuming an ideal saturation-recovery equation based on the Bloch equation [6]. Eight healthy volunteers (32 \pm 13 y.o.) were imaged in a short-axis basal plane at 3T (Tim-Trio, Siemens) at baseline and $10 \mathrm{~min}$ utes following $0.05 \mathrm{mmol} / \mathrm{kg}$ Gd-DTPA injection. All images were acquired in mid-diastole with appropriate

NYU Langone Medical Center, New York, NY, USA

trigger delay. Imaging parameters included: FOV $=350 \mathrm{~mm} \times 272 \mathrm{~mm}$, matrix $=144 \times 112, \mathrm{TE} / \mathrm{TR}=1.2 /$ $2.4 \mathrm{~ms}$, flip angle $=10^{\circ}$, in-plane resolution $=2.4 \mathrm{~mm} \times 2.4 \mathrm{~mm}$, GRAPPA $\sim 1.65$, temporal resolution $=162 \mathrm{~ms}$, and receiver bandwidth $=990 \mathrm{~Hz} /$ pix. For validation purposes, myocardial $\mathrm{T}_{1}$ were compared to reference $T_{1}$ measurements using multi-point $S R$ with TurboFLASH readout ( 20s-breath-hold): 1 PDw-image, $12 \mathrm{~T}_{1} \mathrm{w}$-images with TD 100 to600ms every $100 \mathrm{~ms}$, then 800 to $1800 \mathrm{~ms}$ every $200 \mathrm{~ms}$. A nonlinear LevenbergMarquardt algorithm was used to fit the normalized multi-point SR data. The proposed $\mathrm{T}_{1}$-mapping method was also evaluated in a patient with arrhythmia, before and $20 \mathrm{~min}$ after administrating $0.15 \mathrm{mmol} / \mathrm{kg}$ Gd-DTPA.

\section{Results}

Myocardial $T_{1}$ measured using the proposed rapid method were linearly correlated with $\mathrm{T}_{1}$ measured using the multi-point $\mathrm{T}_{1}$ method (Fig. 1, slope $=0.99$,

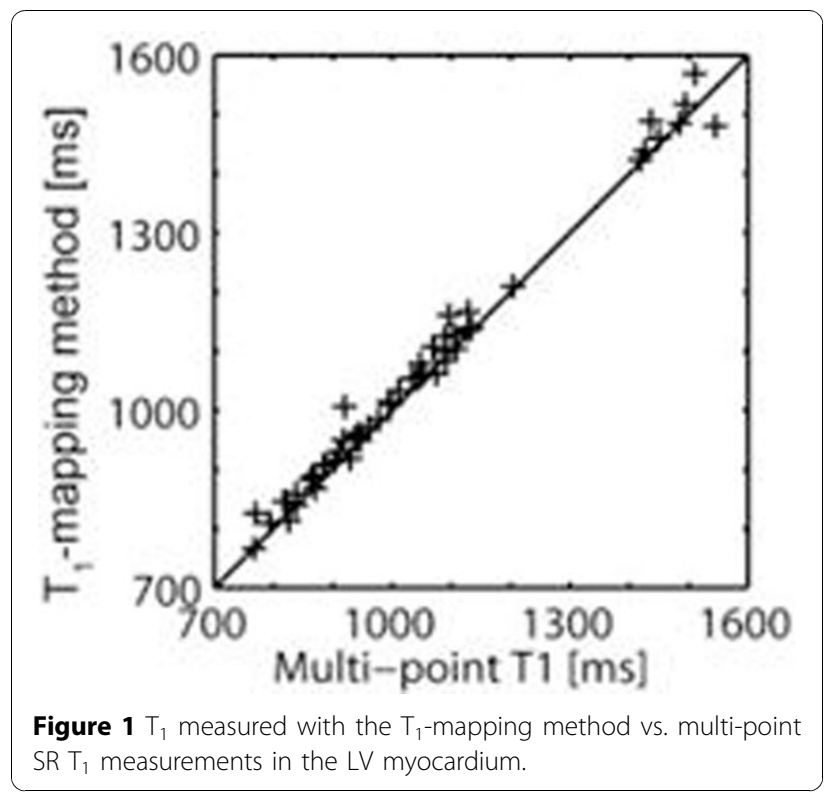




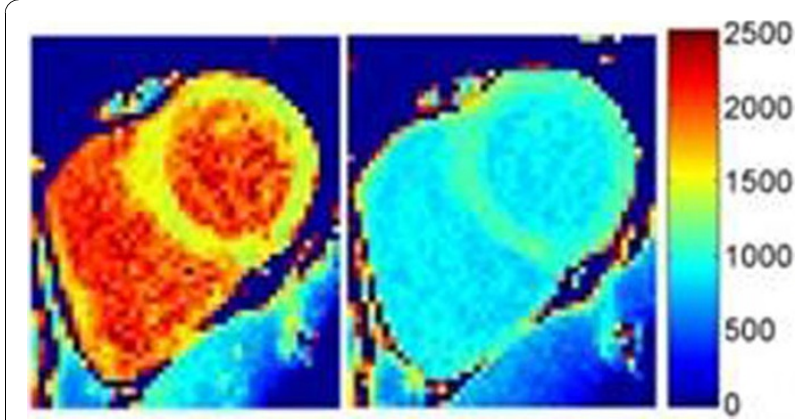

Figure $2 \mathrm{~T}_{1}$-maps obtained in a volunteer before and $10 \mathrm{~min}$ after $0.05 \mathrm{mmol} / \mathrm{kg}$ bolus injection.

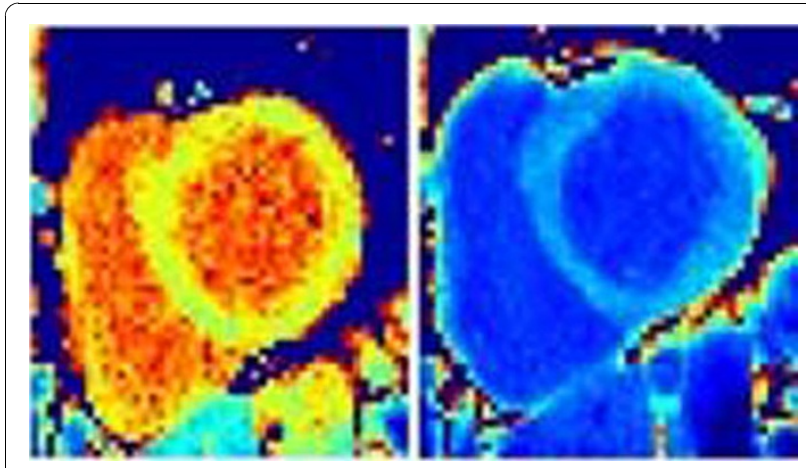

Figure $3 \mathrm{~T}_{1}$-maps obtained in a patient with arrhythmias before and $10 \mathrm{~min}$ after $0.15 \mathrm{mmol} / \mathrm{kg}$ slow injection.

bias $\left.=29 \mathrm{~ms}, \mathrm{r}=0.99, \mathrm{P}<10^{-5}\right)$. Pre- and post-contrast $\mathrm{T}_{1}$-maps obtained in a 52 y.o.-volunteer and a 44 y.o.patient with arrhythmia are shown in Fig. 2-3, respectively (same $\mathrm{T}_{1}$-scale).

\section{Conclusion}

The proposed $T_{1}$-mapping method is a fast pixel-wise $\mathrm{T}_{1}$-mapping technique with insensitivity to cardiac motion and arrhythmia. Future work includes evaluation in patients with acute and chronic infarction.

\section{Published: 2 February 2011}

\section{References}

1. Kim RJ, et al: NEJM. 2000, 243:1445-1453.

2. Kellman P, et al: Magn Reson Med. 2002, 47:372-383.

3. Abdel-Aty H, et al: Circulation. 2004, 109:2411-2416.

4. Messroghli DR, et al: Magn Reson Med. 2007, 34-40.

5. Kim D, et al: Magn Reson Med. 2009, 62:1368-1378.

6. Cernicanue A, Axel L: Acad Radiol. 2006, 13:686-693.

doi:10.1186/1532-429X-13-S1-0107

Cite this article as: Breton et al:: Rapid cardiac T1 mapping within two heartbeats. Journal of Cardiovascular Magnetic Resonance 2011 13(Suppl 1): 0107.

\section{Submit your next manuscript to BioMed Central} and take full advantage of:

- Convenient online submission

- Thorough peer review

- No space constraints or color figure charges

- Immediate publication on acceptance

- Inclusion in PubMed, CAS, Scopus and Google Scholar

- Research which is freely available for redistribution 